ORIGINAL ARTICLE

\title{
Descriptive Mapping of Road Traffic Accidents Reported to Red Crescent, Saudi Arabia
}

THAMER ALSLAMAH ${ }^{1 *}$, YOUSEF MOHAMMAD ALSOFAYAN ${ }^{2}$, MONERAH ABDULLAH ALMAZROA ${ }^{3}$, SULTAN MOUSA ALANNAZ ${ }^{4}$, ADIL ABALKHAIL ${ }^{5}$, RIYAZ AHAMED SHAIK ${ }^{6}$, MOHAMMAD SHAKIL AHMAD ${ }^{6}$ ABDULAZIZ BADAR ALMUTAIRI $^{7}$, WALEED KHALID Z ALGHUYAYTHAT ${ }^{7}$

${ }^{1}$ Department of Public Health, College of Public Health and Health Informatics, Qassim University, Qassim, Saudi Arabia.

${ }^{2}$ Emergency Medicine Consultant, Executive Administration of Medical Affairs, Saudi Red Crescent Authority, Riyadh, Saudi Arabia.

${ }^{3}$ General Manager of Emergency Medical Registry Department, Saudi Red Crescent Authority, Riyadh, Saudi Arabia.

${ }^{4}$ Director of Public Health Department, King Saud Hospital, Unaizah City, Saudi Arabia.

${ }^{5}$ Department of Public Health, College of Public Health and Health Informatics, Qassim University, Al Bukairiyah, Saudi Arabia.

${ }^{6}$ Department of Community Medicine/ Public Health, College of Medicine, Majmaah University, Al Majmaah-11952, Saudi Arabia.

${ }^{7}$ College of Medicine, Majmaah University, Al Majmaah-11952, Saudi Arabia

Correspondence author: Thamer Alslamah, Department of Public Health, College of Public Health and Health Informatics, Qassim University, Qassim, Saudi Arabia.

\begin{abstract}
Introduction: Traffic accidents continue to have serious health and economic consequences all around the globe. Despite significant efforts to enhance road safety, the number of traffic accidents has continuously risen over the past three decades.

Objective: This current study was conducted to determine the cause, injuries, and management problems of road traffic accidents, so that they may be addressed to enhance patient care and reduce morbidity and mortality.

Method: The descriptive study used retrospective record-based data from the Saudi Red Crescent Authority from the duration of 2016-2020. Information collected included: age, sex, incidence by area, frequency in city limits, type of incidence, source of information about the incidence, and distribution of nationality.

Results: The study revealed that males suffered more accidents $(88.5 \%)$ than females $(11.5 \%)$. When we observed these incidences in various areas of Saudi Arabia, it was found that the capital city of Riyadh (21.4\%) had the highest incidences, followed by Makkah (15.2\%).

Conclusion: The scope of the issue of traffic accidents, as well as the resulting loss of human and economic resources, is immense. To address this issue, a national plan must be implemented. The main focus should be on accident prevention, which should be accomplished via health education.

Keywords: Accident, Saudi Arabia, Road Traffic, Red Crescent, Survey
\end{abstract}

\section{INTRODUCTION}

Traffic accidents continue to have serious health and economic consequences all around the globe. Despite significant efforts to enhance road safety, the number of traffic accidents has continuously risen over the past three decades ${ }^{1}$. According to 2009 statistics, there were 1.2 million road accident deaths globally, with 6458 deaths in Saudi Arabia alone 2 . There were 50 million injuries globally, including 36489 in Saudi Arabia ${ }^{3}$. In addition, it was discovered that 18 people die and 100 people are injured every day in Saudi Arabia ${ }^{4}$. The yearly cost of road accidents in Saudi Arabia is projected to surpass $\$ 6$ billion dollars, without including additional social, health, and economic consequences such as disability, rehab, and unemployment as a result of traffic accident injuries 5 . According to reports, road accidents caused 81 percent of fatalities at the Ministry of Health Hospital, while traffic accident victims filled one-fifth of hospital beds 6 . Unfortunately, these figures might be higher; according to previous research, about $60 \%$ of accidents in Saudi Arabia are not recorded for a variety of reasons ${ }^{7}$. Despite the fact that Saudi traffic rules and regulations say that reporting any kind of traffic accident is mandatory ${ }^{8}$. Several studies have shown that the majority of traffic accidents are caused by the characteristics of drivers and other road users ${ }^{9}$. Drivers were directly responsible for about 85 percent of total accidents in Saudi Arabia, according to studies, with surveyors concluding that drivers aged 18 to 40 were involved in approximately 65 percent of traffic accidents in the Asir region of Saudi Arabia, with more than 90 percent of young adults in the Gulf region owning vehicles ${ }^{10}$. Furthermore, experts pointed out that there were two types of reasons for road accidents in Saudi Arabia: general and specialized causes ${ }^{11}$. A significant rise in cars, expansion of road networks, major national development projects, and an increase in the number of foreign employees were all contributing factors ${ }^{12}$. Specific reasons, on the other hand, included driving mistakes, excessive speed, traffic signal violations, and road and vehicle safety conditions ${ }^{13}$. Some investigators claimed that, in addition to the previously mentioned factors, the age of the drivers, their usage of seatbelts, and their level of education were all significant ${ }^{14}$. The majority of the research emphasized the need for public awareness and education efforts, as well as rigorous law enforcement measures. Some investigators claimed that the 3E's solutions of engineering, education, and enforcement might decrease the frequency and severity of traffic accidents ${ }^{15}$.

The goal of this research was to determine the cause of road traffic accidents, the injuries suffered by victims, and management problems so that they may be addressed in order to enhance patient care and reduce morbidity and mortality.

\section{MATERIALS AND METHODS}

Descriptive study was planned using different possible sources of information for Road traffic accident (RTA) using 
retrospective data obtained from Saudi Red Crescent Authority in the duration 2016-2020. An ethical permission was obtained from the Institution Review board from Deanship of Research, Majmaah University with IRB. No. MUREC-May 31/COM-2021/35-1. The Saudi Red Crescent Authority offers emergency medical services (EMS) to Saudi residents and foreigners in all administrative areas of the kingdom of Saudi Arabia and seeks to mitigate calamities and human suffering without discrimination or segregation in the transaction for any reason. All the individuals who suffered injuries due to road traffic accidents recorded were included in the study. and duplicate cases were removed after filtering. The entries with incomplete information and missing variables were excluded from the study. For the purpose of the study, an RTA was defined as an accident which took place on the road between two or more objects, one of which must be any kind of moving vehicle (Jha and Roy, 2004). Total of 63,737 cases were included in the study after removing the duplicate cases after filtration. Information collected included: age, sex, incidence by area (cities, terrains, etc.), frequency in city limits, type of incidence, distribution of nationality, and descriptive response time parameters were taken into consideration. The reported cause of the road traffic accident was also taken into account. The use or non-use of seat belts was also noted.

Data entry and data analysis was done in SPSS version 25 . Frequencies and percentages were calculated for qualitative variables.

\section{RESULTS}

The study revealed that males suffered more accidents (56376, $88.5 \%)$ than females $(7356,11.5 \%)$ (Table

Table 1: Sex distribution.

\begin{tabular}{|l|l|l|}
\hline Sex & Frequency & Percent \\
\hline Female & 7356 & 11.5 \\
\hline Male & 56376 & 88.5 \\
\hline Total & 63732 & 100.0 \\
\hline
\end{tabular}

Table 2: Age distribution.

\begin{tabular}{|l|l|l|}
\hline Age (in years) & Frequency & Percent \\
\hline$<=15$ & 4162 & 6.5 \\
\hline $16-25$ & 20178 & 31.7 \\
\hline $26-35$ & 22356 & 35.1 \\
\hline $36-45$ & 9600 & 15.1 \\
\hline $46-55$ & 4252 & 6.7 \\
\hline $56-65$ & 2192 & 3.4 \\
\hline$>65$ & 992 & 1.6 \\
\hline Total & 63732 & 100.0 \\
\hline
\end{tabular}

Table 3: Incidence by area

\begin{tabular}{|l|l|l|}
\hline Area & Frequency & Percent \\
\hline Assir & 7864 & 12.3 \\
\hline Eastern Region & 9212 & 14.5 \\
\hline Hail & 2438 & 3.8 \\
\hline Aljouf & 1475 & 2.3 \\
\hline Jazan & 3820 & 6.0 \\
\hline Madina Al Munawara & 5325 & 8.4 \\
\hline Makkah & 9673 & 15.2 \\
\hline Najran & 1375 & 2.2 \\
\hline Northern borders & 1023 & 1.6 \\
\hline AlBaha & 1531 & 2.4 \\
\hline Qassim & 4393 & 6.9 \\
\hline Riyadh & 13656 & 21.4 \\
\hline Tabuk & 1947 & 3.1 \\
\hline Total & 63732 & 100.0 \\
\hline
\end{tabular}

Table 4: Out of City

\begin{tabular}{|l|l|l|}
\hline Out of city & Frequency & Percent \\
\hline No & 43384 & 68.1 \\
\hline Yes & 20348 & 31.9 \\
\hline Total & 63732 & 100.0 \\
\hline
\end{tabular}

Table 5: Type of Incidence

\begin{tabular}{|l|l|l|}
\hline Incidence Type & Frequency & Percent \\
\hline Car rollover & 9490 & 14.9 \\
\hline Crash accident & 48848 & 76.6 \\
\hline Pedestrian & 5394 & 8.5 \\
\hline Total & 63732 & 100.0 \\
\hline
\end{tabular}

Table 6: Source of information about the incidence

\begin{tabular}{|l|l|l|}
\hline Source & Frequency & Percent \\
\hline Electronic paramedic & 1010 & 1.6 \\
\hline ESEFNI App & 35 & 0.0 \\
\hline Telephone conversation (dialing 997) & 62687 & 98.4 \\
\hline Total & 63732 & 100.0 \\
\hline
\end{tabular}

Table 7: Distribution by Nationality

\begin{tabular}{|l|l|l|}
\hline Nationality & Frequency & Percent \\
\hline NON-SAUDI & 216 & 0.3 \\
\hline African & 49 & 0.1 \\
\hline American & 12879 & 20.2 \\
\hline Asian & 160 & 0.3 \\
\hline European & \multicolumn{2}{|l|}{} \\
\hline SAUDI & 50428 & 79.1 \\
\hline Saudi Arabia & 63732 & 100.0 \\
\hline Total &
\end{tabular}

It has been observed that the age group 26-35 is more susceptible to the accident $(22356,35.1 \%)$, followed by the age group $16-25(20178,31.7 \%)$. As compared to other age groups of $46-55(4252,6.7 \%)$ and $<=15(4162,6.5 \%)$ which had significant number of cases, the age groups 56 $65(2192,3.4 \%)$ and $>65(992,1.6 \%)$ attributes to lower number of cases; i.e. half and one-fourth cases (Table 2).

When we observed these incidences in various areas of Saudi Arabia, it was found that the capital city of Riyadh (13656, 21.4\%) had the highest incidences, followed by Makkah (9673, 15.2\%). The Eastern region recorded one of the highest incidences of $14.5 \%$ (9212), followed by Asser $(7864,12.3 \%)$ regions (Table 3$)$.

There are several cities/regions where the frequency lies below $5 \%$. It was quite interesting to see that in the outside of the city (highway roads) fewer accidents have been recorded as compared to the city. In the city limits, the accidents have low to medium severity and are less prone to deaths as compared to high-speed highway accidents (Table 4).

The majority of the reported accidents have been car crash accidents $(48848,76.6 \%)$ and car rollovers (9490, $14.9 \%)$ which are a result of high speeding, negligence, and poor reflexes (Table 5).

The source of information regarding the accidental situation was largely provided through the telephonic mode $(98.4 \%)$ by dialing 997. However, governmental applications (Apps) were not frequently used for the information. Available Apps such as Electronic paramedic and ESEFNI App, play a pivotal role in mediating the information but were found to be less preferred (Table 6).

When it comes to determining the nationality, it was observed that the local Saudi population suffered the major portion $(50428,79.1 \%$ ) of the accident situations, followed by the Asians $(12879,20.2 \%)$ who principally came for career opportunities in the Saudi region. A small number of 
Americans, Africans, and Europeans, who might be workers or tourists, also suffered few $(<0.5 \%)$ tragedies (Table 7).

\section{DISCUSSION}

Males suffered more accidents than females which may be due to their less activeness in driving. The age group 16-35 suffered from more than $60 \%$ of the incidences which may be attributed due to the activeness of specific age group to daily working while the age $<=15$ and $>65$ years resulted due to reduced reflexes of individuals. It was observed that with an increase in age, the frequency of drivers decreased significantly and hence the reported incidence cases. The cities were recorded the highest number of accidents where the reason behind the incidence may be attributed to the frequency of traffic within the city region as well as highway region. The highest incidences of accidents were recorded in the rough terrains due to the presence of large number of accident-prone regions. There are several cities/regions where the frequency lies below 5\% owing to less number of vehicles and underdeveloped regional infrastructures. On highways, vehicles are more prone to accidents as a result of overspeeding and tough terrains and ultimately lead to accidents of higher severity.

Road traffic accidents (RTAs) are becoming a significant issue all over the globe, resulting in massive human and economic losses. According to recent World Health Organization (WHO) statistics, more than 1.25 million people are killed, and 50 million are wounded in road traffic accidents each year across the world. According to estimates, at least one traffic collision happens every minute in Saudi Arabia, resulting in up to 7,000 fatalities and over 39,000 injuries each year. The major causes of RTAs in the province of Hail are investigated in research by Touahmia et al., 2018. The data was gathered via a survey that was designed to assess the impact of influencing factors on the RTA rate. According to the findings, 67 percent of RTAs are caused by human factors, 29 percent by road conditions, and $4 \%$ by car faults. The primary causes of RTAs were shown to be excessive speed and violations of traffic laws and regulations. There was also a lack of compliance with speed limit signs and seatbelt requirements. These results comply with our data and thoroughly emphasize the need to enhance road safety and increasing public awareness, as well as strengthening effective traffic law enforcement ${ }^{16}$.

In a research from 2003 to 2013 , yearly data from 13 Saudi Arabian regions were recorded. The fixed effect, random effect, and pooled ordinary least square regression models were used to evaluate the data. Temperature, sandstorms, rainfall, and the number of cars were statistically and substantially responsible for RTAs in Saudi Arabia throughout the research period, according to the results. RTAs produced substantial injuries both within and outside cities, but only RTAs inside cities caused considerable mortality, according to the research. Furthermore, only motor vehicle accidents were shown to have a statistically significant mortality rate from RTA injuries. Understanding the impact of climate change on RTAs aided policymakers in taking the appropriate steps to minimize the negative effects of climate change ${ }^{17}$. This study provided some support for deriving some of the reasons for the accidents within the city and outside of the city.

Automobile accidents are the biggest cause of mortality among teenagers and young people throughout the globe. Road deaths account for almost three-quarters of all mortality in developing nations, with males accounting for $80 \%$ of all fatalities. The rate of four-wheeled vehiclerelated road traffic accidents is the highest internationally recorded road traffic accident figure. The motor vehicle is the primary mode of transportation in Saudi Arabia, with one person killed and four wounded per hour. Vehicles traveling at excessive speeds and/or drivers ignoring traffic signals caused over 65 percent of accidents. Victims, their families, and countries as a whole suffer significant economic losses as a result of road traffic injuries. To reduce mortality and morbidity among adolescents and young people, different sectors (health, police, transportation, and education) should adopt strategic preventive strategies as soon as possible. A key step in implementing the worldwide Decade of Action for Road Safety will be strong and effective cooperation between the Ministry of Health and other ministries, as well as the WHO and other relevant organizations ${ }^{18}$. When compared with the data stated in Table 5 on types of incidences and Table 7 on nationality, it was found to be quite an in agreement but amplified twice in reference to the escalating time.

Young people, particularly men, are the at-risk of road traffic accidents and accounted for the majority of trauma admissions to hospitals. According to the research by Khan et al., 2010, the most commonly damaged body areas were the head and neck, followed by the upper limbs and lower limbs (Khan et al., 2010). According to the report by Ghaffar and Ahmed, 2015, vehicle traffic accidents result in about 19 fatalities and 4 injuries each day. As a result, there is a pressing need to collect comprehensive demographic baseline statistics and injury patterns that will offer scientific evidence-based data to effectively educate the public about road safety. It will also assist in the planning of suitable actions that were previously missed in order to avoid such deaths and long-term disabilities. The data published by Ghaffar and Ahmed and our studied data clearly complied and confirmed that young individuals are at more risk of accident than middle-aged people owing to lesser experience and more negligence (Ghaffar and Ahmed, 2015).

Our study somewhat matched with one of the previously reported data on road traffic accidents reported in Najran City, where most of the RTAs' cases (92\%) were male victims with the highest peak in the age group $20-29$ years. $58 \%$ of the RTAs happened in the evening $6: 00$ PM-9:00 PM), while 20\% occurred in the morning. Head injury represented the most frequent pattern (36\%) followed by spinal injury (23\%), lower limb injury (23\%), upper limb injury $(20 \%)$, thoracic injury $(17 \%)$, pelvic injury, and abdominal injury (8\%). $4.4 \%$ of RTAs resulted in death, whilst $9 \%$ of cases experienced neurological deficits. The researchers concluded that young male drivers in Najran recorded the highest frequency of RTAs which also matched with our conclusions and observations ${ }^{20}$. This data justifies the intensity of injuries among the young drivers that completely supported the conclusions from our data. This data justifies the intensity of injuries among the 
young drivers that completely supported the conclusions from our data.

\section{CONCLUSION}

The scope of the issue of traffic accidents, as well as the resulting loss of human and economic resources, is immense. To address this issue, a national plan must be implemented. The main focus should be on accident prevention, which should be accomplished via health education. There are already plans in the works to spread the message of road safety to the general public via the media, but this should be accompanied by rigorous law enforcement processes to guarantee safe driving. The information interpreted from this descriptive study was propagated to promote awareness among the youth on various aspect of the road traffic accident.

Acknowlegment: The authors would like to thank the Saudi Red Crescent Authority, Riyadh, Saudi Arabia, for sharing the data and the Deanship of Scientific Research, Qassim University for funding this project.

Author Contributions: Conceptualization: Thamer Alslamah; methodology: Yousef Mohammad Alsofayan, Abdullah Almazroa.; software: Riyaz Ahamed Shaik; validation: Mohammad Shakil Ahmad; formal analysis: Riyaz Ahamed Shaik, Adil Abalkhail; investigation: Adil Abalkhail.; resources: Sultan Mousa Alannaz.; data curation: Abdulaziz Badar Almutairi and Waleed Kahlid Z Alghuyaythat.; writing: Thamer Alslamah, Adil Abalkhail; writing-Riyaz Ahamed Shaik and Mohammad Shakil Ahmad; visualization: Sultan Mousa Alannaz; supervision: Thamer Alslamah.; project administration, Yousef Mohammad Alsofayan; all author have read and agreed to the published version of the manuscript

Funding: This study was not funded.

Conflict of Interest: The authors declare that there are no conflicts of interests.

Ethical approval for study: The study was approved by the Medical Ethics Committee of Majmaah University (ethical approval code: MUREC-May 31/COM-2021).

\section{REFERENCES}

1 Shanks NJ, Ansari M, Ai-Kalai D. Road traffic accidents in Saudi Arabia. Public health. 1994;108(1):27-34.

2 Mansuri FA, Al-Zalabani AH, Zalat MM, Qabshawi RI. Road safety and road traffic accidents in Saudi Arabia: A systematic review of existing evidence. Saudi Med J. 2015;36(4):418-24.

3 Ansari S, Akhdar F, Mandoorah M, Moutaery K. Causes and effects of road traffic accidents in Saudi Arabia. Public Health. 2000;114(1):37-9.
4 Ofosu JB, Abouammoh AM, Bener A. A study of road traffic accidents in Saudi Arabia. Accident Anal Prevent. 1988;20(2):95-101.

5 Al-Zahrani AH, Jamjoom MM, Al-Bar HO. Traffic Accident Characteristics in Jeddah, Saudi Arabia. Eng Sci. 1994;6(1):69-80.

6 Yagoub U, Saiyed NS, Rahim BE, Musawa N, Al Zahrani AM. Road traffic injuries and related safety measures: a multicentre analysis at military hospitals in Tabuk, Saudi Arabia. Emerg Med Int. 2021;2021.

7 Al-Rodhan N, Lifeso RM. Traffic accidents in Saudi Arabia: an epidemic. Annal Saudi Med. 1986;6(1):69-70.

8 Qayed $\mathrm{MH}$. Epidemiology of road traffic accidents in AlAhssaa Governorate, Saudi Arabia. East Mediterr Health J. 1998;4(3):513-9.

9 Issa Y. Effect of driver's personal characteristics on traffic accidents in Tabuk city in Saudi Arabia. J Transp Lit. 2016;10:25-9.

10 Alotaibi $\mathrm{F}$, Alqahtani $\mathrm{AH}$, Alwadei A, Al-raeh HM, Abusaq I, Mufrrih SA, Alqahtani AA, Alsabaani A, Alsulami MM. The pattern of orthopedic injuries among Victims of Road Traffic Accidents in Aseer region, Saudi Arabia. Annal Med Surg. 2021:102509.

11 Bener A, Jadaan KS. A perspective on road fatalities in Jeddah, Saudi Arabia. Accid Anal Prev. 1992;24(2):143-8.

12 Badawi IA, Alakija W, Aziz MA. Road traffic accidents in Asir region, Saudi Arabia: pattern and prevention. Saudi Med J. 1995;16:257-64.

13 Al-Ghamdi AS. Analysis of traffic accidents at urban intersections in Riyadh. Accid Anal Prev. 2003;35(5):717-24.

14 Bener A, Abouammoh AM, Elkahlout GR. Road traffic accidents in Riyadh. J Royal Soc Health. 1988;108(1):34-6.

15 Mufti MH. Road traffic accidents as a public health problem in Riyadh, Saudi Arabia. J Traff Med. 1983;11:HS-036654.

16 Touahmia M. Identification of risk factors influencing road traffic accidents. Eng Technol Appl Sci Res. 2018;8(1):241721.

17 Islam M, Alharthi M, Alam M. The impacts of climate change on road traffic accidents in Saudi Arabia. Climate. 2019;7(9):103.

18 Al Turki YA. How can Saudi Arabia use the decade of action for road safety to catalyse road traffic injury prevention policy and interventions?. Int J Injury Contr Safety Promot. 2014;21(4):397-402.

19 Ghaffar UB, Ahmed SM. A review of road traffic accident in Saudi Arabia: the neglected epidemic. Indian J Forensic Commun Med. 2015;2(4):242-6.

20 Al-Zamanan MY, Al-Yami AS, Al-Najrani AA, Al-Asmari MY, Manaa AA, Al-Qahtani AM, Shalayel MH, Elbashir AM, Alsareii SA. Injury pattern among road traffic accidents' victims in najran city, Saudi arabia. Int $\mathrm{J}$ Clin Med. 2018;9(04):270-80 